\title{
Public experiments: understanding public dialogue as an embedded democratic innovation in UK climate governance
}

\begin{abstract}
This chapter explores climate experiments and governance innovations in the context of the institutionalisation of practices of public participation in climate governance, drawing from approaches in the STS (science and technology studies) literature and political science. It does this by drawing on in-depth ethnographic work on institutionalised approaches to public participation in the UK Government, namely the 'public dialogue' processes supported by Government-funded expert body Sciencewise around different science policy issues related to climate governance. Recent criticisms of institutionalised practices of public participation have characterised these processes as laboratory experiments, closely framed and controlled in order to produce legitimate and acceptable outcomes. However, work on the histories, philosophies and geographies of scientific experimentation continually draws attention to the continual overflowing of laboratory experiments; showing that they are always social, and always have the potential break out of their narrow framings and controlled settings.
\end{abstract}

Sciencewise's public dialogues are studied as one particular 'democratic innovation' in climate governance, characterising a set of governance and democratic practices, materials and procedures which have developed and become standardised over time. Thus, the public dialogue approach has a traceable history and potential future trajectories like any other innovation. The public dialogue approach accounts for many influential governance experiments in UK climate policy, including the 2050 pathways dialogue, the Low Carbon Communities Challenge, public engagement with shale gas and oil, and the Bioenergy Distributed Dialogue. Collectively as part of a broader democratic innovation, and individually as participatory experiments these public dialogues have had multiple overflowing impacts, beyond the 'laboratory experiment', encompassing changing framings of climate policy issues, evolving understandings of participation, and contrasting imaginaries of the role of citizens. Furthermore, these effects have overflowed into different national, issue and governance domains, for example, influencing the Japanese government, approaches to research governance in research councils, and inspiring new modes of public engagement around issues such as healthcare. In exploring these multiple open-ended, overlapping and interconnected experiments, this chapter demonstrates the impossibility of wholly bounding governance experiments or identifying where they end. In climate governance and public participation there is the continual potential for objects to go beyond the experiment and contribute to broader governance innovations.

\author{
Authors \\ Helen Pallett, Lecturer in Human Geography of the Environment, School of Environmental \\ Sciences, University of East Anglia, UK
}

Keywords: public participation, public dialogue, democratic innovations, Sciencewise, overflows, energy policy 


\section{Table of contents}

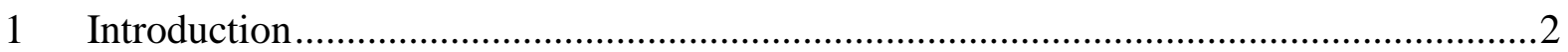

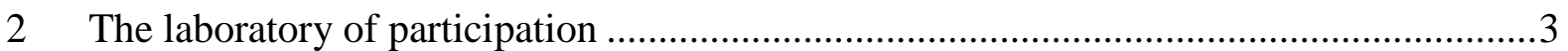

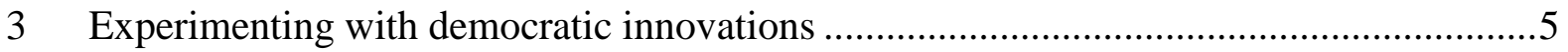

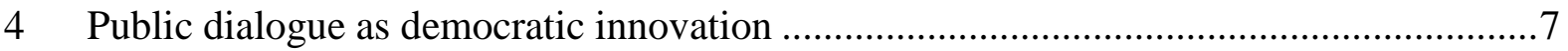

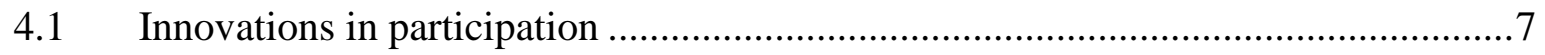

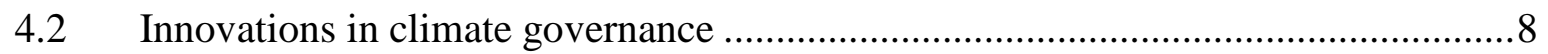

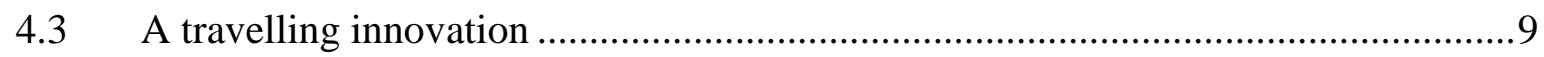

5 Participation overflowing the laboratory: going beyond experiments? ......................... 10

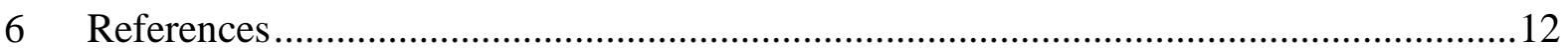

\section{Introduction}

For the last decade or more, there has been a large degree of consensus among policy actors, civil society groups and academics that the scale and scope of the transitions required to address the multifaceted challenge of climate change necessitates engagement and dialogue with citizens (Pallett \& Chilvers, 2013). Therefore, techniques for public participation and engagement have played a central role in climate governance, helping to identify and describe the nature of the challenge, developing interventions to further climate change mitigation and adaptation measures, as well as challenging or holding to account the actions of governing institutions. As has been demonstrated in relation to environmental governance more broadly (Munton 2003; Brown 2009), public participation has been increasingly institutionalised in climate governance structures to the extent that it is difficult to identify decisions and interventions around which no public engagement has taken place (Pallett \& Chilvers 2013). Furthermore, this institutionalisation can be observed at multiple scales and in many domains, with public participation techniques being routinely adopted by departments and agencies of local, national and transnational government, as well as by NGOs and charities, businesses, and scientific institutions such as universities and research councils.

To go beyond the conventional focus on the quality and impacts of individual participation or governance processes, and to engage with the incipient institutionalisation of participation, this analysis focuses on a particular technique of public participation and climate governance - namely the UK Government's public dialogues, which it has been carrying out and promoting for more than a decade. There are multiple forms of experimentation at play in and around the practice of public participation. Perhaps most obviously, participation processes themselves have been characterised as experiments, in the sense of being tests of particular policies and knowledge claims. But these processes also play an important role in broader experiments in policy learning and the politics of ordering collective reality around climate change polices (cf. Turnheim et al., this volume).

This chapter explores these multiple experiments around institutionalised public participation processes using the concept of democratic innovations. This concept comes from the political science literature and has been used to refer to the creation and institutionalisation of new techniques for public participation (Smith 2009). It also has resonances with related work in 
human geography and science and technology studies (STS) concerned with techniques of participation, which has taken more seriously the implications of analysing these practices as innovations or technologies (Voß 2016; Peck \& Theodore 2015). This chapter develops the concept of democratic innovations further in reference to this work, and to debates about experimentation in human geography, STS and the history of science, through the case study of public dialogue.

The UK Government's public participation expert resource centre Sciencewise has been developing and promoting the technique of public dialogue since its creation in 2004. During this time the programme has supported more than 50 public dialogue processes in partnership with different Government departments, agencies or research councils, more than a third of which have directly engaged with climate governance. Some of the most prominent examples of climate related public dialogues include the Big Energy Shift, the 2050 pathways dialogue and the Low Carbon Communities Challenge, all of which were co-sponsored by the Department for Energy and Climate Change (DECC), whilst other dialogues have included topics as diverse as bioenergy, climate change adaptation, geoengineering, flood preparedness and shale gas. The empirical material presented in this chapter comes from two phases of qualitative research on the Sciencewise programme. The first phase was a historical study of the emergence and changes in the Sciencewise programme 2000-2010 carried out with semi-structured interviews and document analysis in 2011 (see Pallett \& Chilvers 2013), and the second phase was an ethnography of the programme carried out throughout 2013 including participant observation, semi-structured interviews, and document analysis (see Pallett 2015).

This chapter is structured as follows. Section 2 considers the relevance of metaphors of experimentation to the study of democracy and participation. Building on this, section 3 introduces and explores the analytical value of the concept of democratic innovations. Section 4 then describes and examines the case of Sciencewise's public dialogues as a democratic innovation. Finally, section 5 considers the different ways in which these experiments have overflowed their bounds, with significant implications for climate governance and public engagement.

\section{The laboratory of participation}

The emergence of increasingly institutionalised and standardised modes of participation has been the subject of growing criticism from STS scholars. Bogner expresses this argument perhaps the most eloquently by describing the forms of participation currently adopted by governing institutions as taking the form of a laboratory experiment (Bogner 2012). This metaphor highlights the level of control exerted through the orchestration of these processes, driven by the concurrent professionalization and commercialisation of participatory practices. The participation laboratory (participation process) is a closed environment which contains a particular set of apparatus (methods of participation) and which only some citizens are permitted to enter; furthermore the aims and the rules of the participation experiment are predetermined by the orchestrators of the experiment (the institutional commissioners and facilitators). Here Bogner and other authors highlight the narrowing set of methods which are considered to be 'best practice' in public participation (Chilvers 2008a; Cooke \& Kothari 2001). It has also been observed that this narrowing of methods has created an increasingly exclusive group of participation experts or mediators, with the power not only to define what constitutes good and bad participation, but to design and carry out participation processes, and to speak on behalf of citizens in the context of science policy (Chilvers 2008b; Gisler \& Schicktanz 2009; Osborne 2004). Therefore the sealed laboratory of participation not only has implications for how citizens are engaged and constructed, but also what is considered a 
legitimate object for participation in the first place, what outcomes of a participation process will be made public, and how they will be made public (Elam et al. 2007).

However, there are more expansive ways to interpret this metaphor which better account for the more disorganised and contingent realities of experimentation. Philosophers and historians of science have also drawn attention to the messy social processes around supposedly bounded and tightly controlled experiments. Through the study of $20^{\text {th }}$ century microphysics historian Peter Galison (1987) argued that the decision to end a particular experiment, when it is believed that enough evidence has been accumulated to authoritatively prove or disprove an assertion, is fundamentally a social one. In other words, even in the world of physics it is impossible to demonstrate that a question has been definitively closed or that disturbing effects have been completely removed from the experimental setting. Furthermore, in relation to the history of the natural sciences, the philosopher Ian Hacking (1983) characterises the relationship between experiments and scientific theories as a recursive one, with neither aspect entirely determining the other. Experiments may be interpreted and designed in line with certain working theories or more general concepts, but the outcomes of experiments may also lead to the creation of new conceptual objects which become involved in the design of new experiments. Consequently in Hacking's account, scientific theory, experimental practice and broader social influences interact to produce scientific facts and to initiate new experiments, rather than one factor being the driving force.

This recognition of the never quite complete nature of experimentation has also been productively elaborated by geographers and STS scholars to draw attention to the continual existence of overflows from experimentation over space and time. Several authors have empirically demonstrated the ways in which scientific experiments go beyond the boundaries of the laboratory through the application of new technologies and knowledges to 'real-world' problems and their concurrent effects on modes of social organisation (Hinchliffe et al. 2005; Schwartz \& Krohn 2011; Szerszynski 2005). This has led the geographer Gail Davies (2010) to argue that it is not only important to question when experiments end but also where they end. Others have labelled this as a broader regime of collective experimentation (Felt \& Wynne 2007) or as a series of 'wild experiments' (Lorimer \& Driessen 2013), evoking a picture of a multiplicity of open-ended experiments playing out at multiple scales within a democratic regime, with varying degrees of intentionality by the actors involved. In parallel to this Callon et al. (2009) have elaborated the phenomena of 'participation in the wild', evoking a similar overflowing of processes and effects from the participation laboratory.

The concept of a regime of collective experimentation has particular resonance with discussions of governance or democratic innovations. As laid out in the European Commission report 'Taking the European Knowledge Society Seriously' (Felt \& Wynne 2007) collective experimentation is characterised by the broad distribution of innovation across different actors and communities, trying out novel responses to societal challenges and learning from their repeated attempts or experiments both in innovation itself and in the governance of innovation. The term 'collective experimentation' has also been used by Bruno Latour, but with a broader meaning encompassing the system-wide consequences of human interventions, such as climate change (Latour 2011). Furthermore, Matthias Gross has built on this work to show the relevance of concepts of collective experimentation to ecological interventions on the ground, enacted by experts, citizens and policy actors in collaboration (Gross 2010a; Gross 2010b).

Democracy itself had been conceptualised as an experiment perhaps most influentially in John Dewey's book 'The public and its problems' where he argues that even the formation of the state is an experimental process, consisting of trials and accidents around new rules and organisations (Dewey 1927). Publics come into being and become organised in response to new policy problems which are made up of these unforeseen indirect consequences, leading to new political institutions and forms of organisation. Crucially, the experiment must 
constantly be repeated as the state is continually discovered anew as novel challenges and publics arise. In this view democracy is not a stable entity or benchmark, but rather something that is continually practiced and contested (cf. Gallie 1956). Understandings of democracy are not static but change over time in response to the emergence of new public problems and following developments in science and technology. Furthermore there is change in collective understandings of who is being represented in a democracy, the appropriate relationship between the state and its citizens, and what sort of knowledge can legitimately be drawn upon in political processes (Jasanoff 2011).

\section{Experimenting with democratic innovations}

It could be said that through experiments like climate governance and public participation new meanings of democracy, new definitions of public problems and new modes of engaging citizens are being produced. The concept of democratic innovations offers one analytic lens through which to describe and understand these processes, as well as drawing attention to the broader reconfigurations of relationships between citizens, science and the state which emerge from the multiple, open-ended and overlapping experiments of democratic governance in societies infused with science and technology (Callon et al. 2009; Ezrahi 1990; Jasanoff 2011).

Concepts like governance innovations and democratic innovations owe much to a broader literature which focusses on social innovations, broadly defined as innovations in social practices or forms of social organisation such as institutions (cf. Pol \& Ville 2009). The key conceptual move made here is to argue that particular procedures or bundles of practices can become more or less standardised - just like other forms of innovations - and can therefore travel into different political contexts and have multiple indirect effects as has been noted in the broader innovation literature (Fagerberg 2006). Discussions of social innovation have been particularly significant in the fields of environmental governance, and citizen action and participation (e.g. Gottweis et al. 2007; Seyfang \& Smith 2007). The concept does at least two important things with regards to understandings of governance. First, accounts of social innovations often draw attention to issues of justice and societal wellbeing, rather than purely technically defined societal aims and measures of progress (Dawson \& Daniel 2010). Secondly, and most significantly, the concept highlights that progress in addressing societal challenges such as climate change is not only dependent on technical innovations and fixes, but rather will also be achieved - or perhaps even primarily achieved - through changes in social practices and forms of organisation (Seyfang \& Smith 2007). Thus the concepts of social, governance and democratic innovations are a useful challenge to dominant technically-led or even technocratic visions of energy transitions and climate change governance.

The political scientist Graham Smith was one of the earliest and probably among the most prominent analysts to offer a definition and empirical elaboration of the term 'democratic innovations' in his book of the same name (Smith 2009). Smith defines democratic innovations as "institutions that have been specifically designed to increase and deepen citizen participation in the political decision-making process" (Smith 2009: 1), using the concept to describe and analyse standardised modes of citizen participation including participatory budgeting and citizens panels. For Smith these practices are innovative in that they represent a departure from conventional institutional architectures (Smith 2009). However, in light of broader literatures on technical and social innovations there is more to unpack in this concept of democratic innovations.

First there are other social innovations which could also be labelled as democratic innovations, beyond the invited deliberative processes of citizen participation which Smith 
considers. Established governmental modes of citizen engagement such as consultations and public opinion polls were once novel democratic innovations, whilst more emergent policy practices of citizen engagement such as open policy approaches and open data could be considered as democratic innovations in the making. Furthermore, whilst Smith states that his concept of democratic innovations concerns only highly institutionalised practices, it is also possible that democratic innovations could become standardised and institutionalised outside of formal governing institutions. For example, practices of community organisation such as co-operatives or community currencies, alongside widely practiced forms of activism such as direct action or petitioning, could become standardised and might also be considered to be democratic innovations (cf. Seyfang \& Smith 2007).

Secondly, there is potential mileage in taking the 'innovation' part of democratic innovations more seriously. Work in STS, innovation studies and the social studies of technology has offered further insights into processes of innovation by giving detailed histories of innovation processes which highlight their contingencies and the social processes which have shaped them (e.g. Pinch \& Bijker 1987), as well as pointing to their potential future trajectories and identifying path-dependencies (Berkhout 2002; Fagerberg 2006). Furthermore, many accounts have highlighted the unintended consequences which emerge from technological innovations, sometimes with very significant impacts for society (Irwin 1995), as well as the broader effects which innovation processes have on modes of social organisation (Jasanoff 2004). This has led to many calls for and attempts to orchestrate procedures for what has been labelled as anticipatory governance, reflexive governance (Beck 1994), constructive technology assessment (Schot \& Rip 1997), and - most recently - responsible innovation (Stilgoe et al. 2013), in order to more fully take into account the social dimensions and potential effects of innovations. This work suggests that it might be possible too, to think of democratic innovations as also having these complex and contingent social histories, potential trajectories and path-dependencies, and broader societal effects. If this is the case, there is an important role for academic analysis in identifying and describing these dimensions, as well as finding ways to anticipate, govern and be responsible for the potential effects of these innovations.

A small group of STS scholars has already made some advances in this project, held together under the labels of technologies of participation or democracy. Using this conceptual framework, authors have examined the genealogies or contingent histories of prominent technologies of participation such as the focus group (Lezaun 2007), as well as the kinds of participants (Lezaun \& Soneryd 2007; Marres \& Lezaun 2011), issue-framings (Marres 2007), and forms of action (Laurent 2011) which these technologies produce. Taking further inspiration from innovation studies, Soneryd (2016) has explored how one such technology of participation travelled and was translated into a new national and political context, with implications for its broader social effects and attendant modes of social organisation. Furthermore, these scholars have also started to consider what implications their findings have for the governance of participation, with $\operatorname{Vo} \beta$ (2016) carrying out the first constructive assessment process concerned with participatory methods, and Chilvers and Kearnes (2016) calling for a broader transformation in modes of participation towards a more reflective and reflexive approach. Whilst using the metaphor of a technology to describe procedures of participation arguably runs the risk, similar to the laboratory of participation metaphor, of over-emphasising the bounded and controlled nature of most processes of participation, the situation of these studies within wider work on technological innovation which emphasises the constant production of unintended effects and new forms of social organisation also evokes the sense of open-ended experimentation described at the end of section 2. Many of these authors have also increasingly adopted a language of experimentation (Chilvers \& Kearnes 2016a) to point to the wider experiments in participation and democracy of which these technologies are a part. 


\section{Public dialogue as democratic innovation}

\subsection{Innovations in participation}

At the start of the twenty-first century many of the important institutional developments around science and science policy concerned the putative move towards initiating more of a two-way dialogue with citizens around scientific issues which affected their lives. In the UK this move was characterised as a shift from a focus on the public understanding of science (PUS) towards an emerging approach which emphasised public engagement with science (PES) (Michael 2011; Pieczka \& Escobar 2013). During the 1990s Public Understanding of Science activities were subject to robust academic criticism, labelling the their way of engaging with citizens as the 'deficit model' which assumed citizens were empty vessels needing to be filled with the correct information, in order to accept scientific advances and policy (Irwin 2001; Owens 2000). In the year 2000, in the wake of several large public science controversies, such as the BSE crisis and the MMR vaccine, and the apparent failure of the PUS project, the House of Lords Science and Technology Committee produced the report 'Science and Society' (House of Lords 2000) which called for direct dialogue with the public to become an integral part of science policy-making. At the time, as well as in later accounts, this report was viewed as a pivotal moment in democratic practice around science policy in the UK, setting in train the institutionalisation of a more dialogic form of public engagement with science and science policy (Bickerstaff et al. 2010; Miller 2001). The House of Lords report stimulated discussion in the UK Government calling for public dialogue around science policy (H M Treasury 2004; POST 2001; POST 2002). Perhaps most significantly, this call for direct public involvement in science policy-making resulted in the creation of Sciencewise as part of the 'Science \& Innovation Investment Framework 20042014' (H M Treasury 2004), within what was then the Department for Trade and Industry.

The narrative of the increasing turn to more deliberative and dialogic modes of public interaction in government science policy, in response to public knowledge controversies and distrust of government experts and policies has been continually reinforced in govern ent documents and in academic work (Pieczka \& Escobar, 2013). However, this story arguably obscures the labour of academic and political advocates and the broader political context around the time of the mooted shift from PUS to PES. Social scientists played an important role in advocating and developing deliberative approaches to public participation. In the UK, the institutional move from PUS to PES was supported by establishment figures who had long been involved in supporting government PUS projects, such as the historian of science John Durant, and prominent critics of the PUS approach, such as the STS scholar Brian Wynne, both of whom acted as witnesses for the 'Science and Society' report (House of Lords 2000). STS scholar Charles Thorpe (Thorpe \& Gregory 2010; Thorpe 2010) has also argued that the turn towards public deliberation, and particularly the focus on reaching consensus as a key aim in processes like Sciencewise's public dialogues, is part of the broader development of the post-Fordist public in post-industrial British politics. Thorpe particularly highlights the role of the prominent sociologist Anthony Giddens and the leftwing think tank Demos in laying the groundwork and working with the New Labour project, to bring consensus politics and participatory democracy centre stage (Thorpe 2010).

As described in more detail in Pallett and Chilvers (2013) the Sciencewise programme has undergone several distinct phases in its existence, through which its approach to the practice of public dialogue has evolved as well as its relationship to UK Government policy-making. In its early phase the programme supported projects which were often quite experimental in nature, creating card games or plays for youth engagement around science policy topics, and tended to lack clear connections to Government policy decisions. After the programme's relaunch as an expert resource centre in 2006 the dialogue projects it supported became much more standardised, and a clear definition of public dialogue emerged as featuring: extended 
deliberation over one or more days; two way dialogue between experts, policy-makers and the public; workshops held in different parts of the country with a roughly demographically representative but small group of citizens; the creation of 'balanced' introductory materials for the participants to give them a good understanding of the issues under discussion; advisory structures overseeing the process and the materials the participants were presented with; and a clear policy hook with a government department, agency or research council which the dialogue outputs would feed into.

The practice of public dialogue which was developed took inspiration from what were considered successful examples of public engagement in other European countries, most significantly the Danish Board of Technology and the Rathenau Institute in the Netherlands. The method can also be seen as an at times uneasy amalgamation of earlier democratic innovations which were seen as legitimate in the UK Government context, namely focus group methods and public opinion polling. Thus whilst public dialogues are essential small group deliberative workshops, they are still required to be broadly demographically representative of the UK population - like a public opinion survey - even though the numbers involved are too small to be statistically significant.

The most recent (2012-2016) contract period of the Sciencewise programme saw further changes in institutional arrangements and the practice of public dialogue, as discussed in more detail in Pallett (2015). This contract period saw the involvement of the British Science Association and the participation-focussed body Involve in the day-to-day running of the programme, alongside the original contractor, the consultancy firm AEA. This, alongside the emergence of the open policy debate around the UK Government during this time led to further experimentation around the methods and institutional contexts of public dialogue processes, and involved Sciencewise actors in broader debates about democratic governance and science policy in the UK.

\subsection{Innovations in climate governance}

Since its relaunch as an expert resource centre for public dialogue in 2008, Sciencewise was involved in a number of high profile public dialogue projects around significant UK climate policy issues. The Big Energy Shift (2008-9) was the first public dialogue supported and cofunded by Sciencewise and the Department for Energy and Climate Change (DECC). The dialogue reflected emerging policy interest in behaviour change at the time as a key element of UK climate policy, and aimed to explore why peoples behaviours were not changing in the expected ways in response to information provision and social marketing. This dialogue was important in establishing a productive long-term relationship between Sciencewise and DECC and was credited with spurring the creation of a further DECC-Sciencewise dialogue called the Low Carbon Communities Challenge (2010-2011).

In reality the LCCC was influenced by broader policy agendas concerning behaviour change and the emergence in the UK of community energy. However, the focus on engaging with already active community groups rather than individuals (as is usually the case in a public dialogue) was partly justified as a response to the key finding of the Big Energy Shift: that people's behaviours shift as part of groups rather than on an individual basis. Thinking on behaviour change in other parts of Government was also starting to converge on the potential effectiveness of community-based initiatives, so policy actors saw an opportunity to harness the dynamism of community energy projects in order to promote behaviour change, as in the LCCC. However this blurring between the behaviour change agenda and the community energy movement, which was characterised by a very different vision of the energy system and energy futures, and focussed on energy supply, was also seen as problematic by some academic and civil society commentators. Ultimately, whilst the LCCC was one of the most high profile public engagement projects around climate governance in the UK ever, the 
findings and impacts of the project were disrupted by the change of government in 2010 , which signalled a change in tack on climate and energy policy.

At around the same time Sciencewise and DECC supported another public dialogue project focussed on realising the 2050 greenhouse gas reduction targets laid out in the 2008 Climate Change Act. Here the public dialogue was carried out alongside an expert process and economic assessment, and was concerned with identifying potential pathways through which the targets could be reached and gauging their level of fit with public values. The dialogue's format also contained a number of novel elements including a separate youth panel which met several times during the process, and the creation of an online game which allowed anyone who was interested to join in and explore the possible demand and supply-side options for reaching the targets. This game also structured the public dialogue workshops which focussed on the creation of group and, in some cases, individual preferred pathways to reaching the 2050 targets using these different options.

After the start of the term of the Conservative-Liberal Democrat coalition government in the UK the DECC-Sciencewise relationship continued around less high-profile projects, including some related to the Climate Change Committee and carbon budgets, which continued to address many of the concerns and ideas from the earlier 2050 pathways dialogue. In 2013 the Office of Unconventional Gas and Oil, which sat within DECC, also supported a public dialogue project related to the public controversy around fracking in the UK in partnership with Sciencewise. The dialogue focussed on the narrow issue of how to best compensate communities affected by fracking, rather than allowing a broader discussion of public concerns and values related to the issue.

Sciencewise has also partnered with many other parts of Government in order to support public dialogue projects related to climate policy. For example, a number have been carried out with and for UK Government research councils. A public dialogue project took place alongside the Living with Environmental Change cross-research council programme, exploring public responses to climate change research through a number of workshops in 2010. With the Biotechnology and Biological Sciences Research Council (BBSRC) Sciencewise supported the Bioenergy Distributed Dialogue (2012-2013) focussed around public responses to research into biofuels, a potential but at times controversial contributor to the low carbon transition. This project also attempted to create new methodologies for public dialogues which would allow more sustained and long term engagement with the public, as well as a more iterative relationship between the development of the BBSRC's research agenda and the outputs of dialogue workshops. This was achieved through a card deck which could be altered and added to in response to new research or public responses, and could also be downloaded and used by any group wanting to engage with research on biofuels.

As well as research councils, Sciencewise also partnered with Government agencies to carry out public dialogue projects around climate policy. In collaboration with the Environment Agency and other bodies, Sciencewise supported a public dialogue on the topic of flood preparedness (2012-2013), focussing not only the technical aspects of flood response, but also the need for institutional connections and responsiveness in dealing with flood risk and flooding events.

\subsection{A travelling innovation}

The above account demonstrates how public dialogue as a democratic innovation has successfully travelled to and, in some cases, become embedded in different parts of UK Government climate policy. Public dialogues have fed into climate change research, engaged with controversial topics and technologies like fracking and bioenergy, and been used in relation to concrete pieces of legislation like the Climate Change Act, as well as contributing towards broader policy agendas, such as behaviour change. Beyond Sciencewise's direct interventions public dialogue has also been taken up more broadly as a credible and effective 
method of public engagement by UK research councils, EU research programmes, market research companies, local government and even other governments, including the devolved Scottish Government and Japanese Government. In these ways public dialogue as a democratic innovation has had broader impacts on climate change policy and governance, contributing towards decision-making around specific issues as well as processes of envisioning energy and climate futures.

Beyond individual processes of public dialogue, it is also possible to follow its wider effects on climate governance through widespread usage. While there are variations between processes, public dialogues tend to produce similar visions of citizens and their role in climate governance, similar framings of the climate 'problem', as well as resting on a particular vision of democratic engagement. The model of democracy which characterises this particular democratic innovation is deliberative and consensual, obscuring arguments and actions such as protests and public debates which are more antagonistic in nature - not uncommon around climate change. Furthermore, whatever the climate issue under discussion, the design of public dialogues processes - which makes a strong distinction between public and expert inputs - tends to present climate and energy as primarily technical issue. This is both influenced by and reinforcing dominant visions in climate governance of climate change being a technical issue requiring public behaviour change and acceptance of new technologies, but little broader exploration of public values and actions. Therefore, the publics of public dialogue projects are often imagined in fairly passive roles, and are often seen as having little relevant knowledge of the issues prior to their involvement in the public dialogue process. This strong vision again has resonance and effects more generally in climate governance, limiting the potential roles citizens could play in the transition to a low carbon and climate adapted world. However, in these repeated experiments there is always room for contingency and emergence because the experiment is never quite finished. In some instances public dialogues have adopted different visions of the public or the issue in hand, for example the LCCC was predicated on having much more active and knowledgeable participants. And in other instances assumptions about publics and climate issues have been transformed and challenged during and after the process, for example through unexpected public responses or the take up of public dialogue outputs in unexpected places, such as by civil society organisations.

As an outcome of repeated and overlapping experiments, the impacts of this democratic innovation cannot be limited to the realm of climate governance - even when only climate change related public dialogues are considered. In the examples given above, public dialogue processes also contributed to changing institutional attitudes towards public engagement and the public, for example within DECC and the BBSRC. Through the constant repetition and travel of the public dialogue technique there has also been methodological innovation in order to adapt it to new contexts and aims, or as a result of learning. These new methods create the potential for new forms of engagement - such as the sustained and evolving engagement attempted in Bioenergy Distributed Dialogue - and therefore new ways for citizens to influence policy and governance.

\section{Participation overflowing the laboratory: going beyond experiments?}

There are multiple forms of experimentation at play in this account of the institutionalisation of public dialogue and its effects on climate governance. The initial development of public dialogue as a democratic innovation can be described as experimental process, requiring time and repetition to refine the procedure and approach during the early stages of the Sciencewise programme. Furthermore, this account has demonstrated that experimentation with the approach is ongoing, as it continues to shift to address new contexts, aims and challenges. In common with the existing literature this chapter also finds that there is analytical value in treating individual public dialogue processes themselves as experiments. Moreover they are 
experiments with a number of different concerns, including testing the credibility and acceptability of a set of policy propositions (testing hypotheses), trying out new working relationships (learning by doing), testing new techniques and tools (selecting designs that work) (cf. Turnheim et al., this volume) - such as the 2050 pathways game

(my2050.decc.gov.uk), and trying different ways to influence policy actors and processes. Public dialogue processes have also been part of broader experiments in climate governance, including the internationally unprecedented UK Climate Change Act, the community energy movement and Government attempts to encourage the emergence of a UK fracking industry.

Far from being discrete and controlled, these experiments in participation and climate policy have overflowed the walls of their metaphorical laboratories in a number of ways. They have contributed to social movements, like community energy, beyond the bounds of formal climate policy or invited public engagement. They have also helped to shape and change institutions, for example changing the BBSRC's attitude towards the value of public engagement in the case of the bioenergy distributed dialogue, or showing related Government agencies how they could work more effectively together in the case of the flood response dialogue. They have also had broader effects by contributing to the closing down of certain debates and issue spaces. For example, the fracking dialogue supported by Sciencewise and DECC arguably contributed towards a broader narrowing of the terms of debate about fracking, which denied the validity of broader discussions about public trust or social justice, or the role of fracking in the transition to a low carbon energy system.

Examining experiments around public engagement and climate governance through the lens of one democratic innovation - public dialogue - also illuminates the role of experimentation in processes of organisational and policy learning. Not only do experiments generate new knowledge through testing hypotheses about the world, but they might also contribute to learning by forging new ways of doing climate governance and public engagement, new relationships, new ways of organising and categorising knowledge and activities, and new collective stories. The metaphor of experimentation also helpfully captures the non-linearity and ambiguous nature of these learning processes. Whilst it might have appeared in the context of some public dialogue projects and policy decisions that visions of the role of citizens in climate governance had shifted - for example the LCCC's adoption of a model of active communities providing climate change solutions - other processes and decisions were an apparent backward step. Uncertainty and contingency are ever-present features of experimentation and innovation, and an understanding of the political dimensions of these experiments can often be the most useful element in identifying reasons for their relative success or failure, rather than their levels of embeddedness or standardisation.

The experiments described here are both open-ended and overlapping, influencing and connecting governance at multiple scales, including states, transnational bodies, local governance and individual institutions. This account also demonstrates the overlapping of issue areas through these experiments, including climate, energy, bioscience, and risk and vulnerability. Even where there are no wider effects of a particular experiment yet in evidence, there is always potential for impact and influence to occur long after the initiation of the experiment. For example, elements of particular public dialogue processes get recycled and reused, as is the case with the pathways game created for the 2050 pathways dialogue. Furthermore, the outputs of different experiments which may have appeared irrelevant, inconvenient or useless at the time, may be interpreted differently when taken up within a different institution or movement, or in the light of subsequent unexpected events.

It should not be a surprise that in the context of public engagement and climate governance, the experiment is never finished. Rather, constant monitoring and intervention are needed for the experiment to be reshaped and retried. 


\section{References}

Beck, U., 1994. The Reinvention of Politics: Towards a Theory of Reflexive Modernization. In Reflexive Modernization Politics Tradition and Aesthetics in the Modern Social Order. pp. 1-55. Available at:

Berkhout, F., 2002. Technological regimes, path dependency and the environment. Global Environmental Change, 12, pp.1-4.

Bickerstaff, K. et al., 2010. Locating Scientific Citizenship: The Institutional Contexts and Cultures of Public Engagement. Science Technology \& Human Values, 35(4), pp.474500.

Bogner, A., 2012. The Paradox of Participation Experiments. Science, Technology \& Human Values, 37(5), pp.506-527.

Brown, M.B., 2009. Science in Democracy: expertise, institutions and representation First., Cambridge, Massacheussetts: MIT Press.

Callon, M., Lascoumbes, P. \& Barthe, Y., 2009. Acting in an Uncertain World: An Essay on Technical Democracy Translated., Massacheussetts: MIT Press.

Chilvers, J., 2008a. Deliberating competence - Theoretical and practitioner perspectives on effective participatory appraisal practice. Science, Technology \& Human Values, 33(2), pp.155-185.

Chilvers, J., 2008b. Environmental risk, uncertainty, and participation: mapping an emergent epistemic community. Environment and Planning A, 40(12), pp.2990-3008.

Chilvers, J. \& Kearnes, M., 2016a. Participation in the making: rethinking public engagement in co-productionist terms. In J. Chilvers \& M. Kearnes, eds. Remaking Participation: Science, Environment and Emergent Publics. London: Routledge, pp. 31-63.

Chilvers, J. \& Kearnes, M., 2016b. Remaking participation: towards reflexive engagement. In J. Chilvers \& M. Kearnes, eds. Remaking Participation: Science, Environment and Emergent Publics. London: Routledge, pp. 261-288.

Cooke, B. \& Kothari, U., 2001. Participation: The New Tyranny?, London: Zed Books.

Davies, G., 2010. Where do experiments end? Geoforum, 41(5), pp.667-670.

Dawson, P. \& Daniel, L., 2010. Understanding social innovation: a provisional framework. International Journal of Technology Management, 51(1), p.9.

Dewey, J., 1927. The public and its problems, New York: H. Holt.

Elam, M. et al., 2007. Mediators of Issues and Mediators of Process, Brussels. Available at: http://www.argonaproject.eu/docs/arg-del_4-wp3-final.pdf.

Ezrahi, Y., 1990. The Descent of Icarus, Cambridge, Massacheussetts: Harvard University Press.

Fagerberg, J., 2006. Innovation: a guide to the literature. In J. Fagerberg, D. C. Mowery, \& R. R. Nelson, eds. Oxford Handbook of Innovation. Oxford: Oxford University Press, pp. $1-26$.

Felt, U. \& Wynne, B., 2007. Taking the European Knowledge Society Seriously E. Commission, ed. Report of the Expert Group on Science and Governance to the Science, Economy and Society Directorate, Directorate-General for Research, European Commission, p.96.

Galison, P., 1987. How Experiments End, Chicago: University of Chicago Press.

Gallie, W.B., 1956. Essentially Contested Concepts. Proceedings of the Aristoliean Society, 56, pp.167-198. 
Gisler, P. \& Schicktanz, S., 2009. Introduction: Ironists, reformers, or rebels? Reflections on the role of the social sciences in the process of science policy making. Science, Technology and Innovation Studies, 5, pp.5-17.

Gottweis, H., Braun, K. \& PAGANINI Consortium, 2007. Participatory Governance and Insitutional Innovation: Final Report, Available at: http://www.univie.ac.at/LSG/paganini/finals_pdf/WP8_FinalReport.pdf.

Gross, M., 2010a. Ignorance and Surprise: Science, Society and Ecological Design, Cambridge, Massachusetts: MIT Press.

Gross, M., 2010b. The Public Proceduralization of Contingency: Bruno Latour and the Formation of Collective Experiments. Social Epistemology, 24(1), pp.63-74.

H M Treasury, 2004. Science and Innovation Investment Framework: 2004-2014.

Hinchliffe, S. et al., 2005. Urban wild things: a cosmopolitical experiment. Environment and Planning D: Society and Space, 23(5), pp.643-658.

House of Lords, 2000. Science and Society: the House of Lords Science and Technology Committee Third Report.

Irwin, A., 1995. Citizen Science: A study of people, expertise and sustainable development, London: Routledge.

Irwin, A., 2001. Constructing the scientific citizen: science and democracy in the biosciences. Public Understanding of Science, 10(1), pp.1-18.

Irwin, A., 2006. The politics of talk: Coming to terms with the "new" scientific governance. Social Studies of Science, 36(2), pp.299-320.

Jasanoff, S., 2011. Constitutional Moments in Governing Science and Technology. Science and engineering ethics, 17(4), pp.621-38.

Jasanoff, S., 2005. Designs on Nature: Science and Democracy in Europe and the United States, Princeton: Princeton University Press.

Jasanoff, S., 2004. The idiom of co-production. In States of Knowledge: The co-production of science and social order. Abingdon, Oxon: Routledge, pp. 1-12.

Latour, B., 2011. From Multiculturalism to Multinaturalism: What Rules of Method for the New Socio-Scientific Expertiments. Nature and Culture, 6(1), pp.1-17.

Laurent, B., 2011. Technologies of Democracy: Experiments and Demonstrations. Science and Engineering Ethics, 17(4), pp.649-666.

Lezaun, J., 2007. A market of opinions: the political epistemology of focus groups. Sociological Review, 55, pp.130-151.

Lezaun, J. \& Soneryd, L., 2007. Consulting citizens: technologies of elicitation and the mobility of publics. Public Understanding of Science, 16(3), pp.279-297.

Lorimer, J. \& Driessen, C., 2013. Wild experiments at the Oostvaardersplassen: rethinking environmentalism in the Anthropocene. Transactions of the Institute of British Geographers, p.n/a-n/a.

Marres, N., 2007. The Issues Deserve More Credit: Pragmatist Contributions to the Study of Public Involvement in Controversy. Social Studies of Science, 37(5), pp.759-780.

Marres, N. \& Lezaun, J., 2011. Materials and devices of the public: an introduction. Economy and Society, 40(4), pp.489-509.

Michael, M., 2011. “What Are We Busy Doing?”: Engaging the Idiot. Science, Technology \& Human Values, 37(5), pp.528-554.

Miller, S., 2001. Public understanding of science at the crossroads. Public Understanding of Science, 10, pp.115-120. 
Munton, R., 2003. Deliberative democracy and environmental decision-making. In F. Berkhout, M. Leach, \& I. Scoones, eds. Negotiating Environmental Change: New Perspectives from Social Science. Cheltenham, UK: Edward, Elgar, pp. 109-136.

Osborne, T., 2004. On mediators : Intellectuals and the ideas trade in the knowledge society. Economy and Society, 33(4), pp.430-447.

Owens, S., 2000. "Engaging the public": information and deliberation in environmental policy. Environment and Planning A, 32(7), pp.1141-1148.

Pallett, H., 2015. Public Participation Organizations and Open Policy: A Constitutional Moment for British Democracy? Science Communication, 37(6), pp.769-794.

Pallett, H. \& Chilvers, J., 2013. A decade of learning about publics, participation and climate change: institutionalising reflexivity? Environment and Planning A, 45(5), pp.11621183.

Parliamentary Office of Science and Technology, 2001. OPEN CHANNELS: Public dialogue in science and technology, London. Available at: http://www.parliament.uk/documents/post/pr153.pdf.

Parliamentary Office of Science and Technology, 2002. PUBLIC DIALOGUE ON SCIENCE \& TECHNOLOGY, London. Available at: http://www.parliament.uk/documents/post/pn189.pdf.

Peck, J. \& Theodore, N., 2015. Fast policy: experimental statecraft at the thresholds of neoliberalism, Minnesota: University of Minnesota Press.

Pieczka, M. \& Escobar, O., 2013. Dialogue and science: Innovation in policy-making and the discourse of public engagement in the UK. Science and Public Policy, 40(1), pp.113126.

Pinch, T.J. \& Bijker, W.E., 1987. The Social Construction of Facts and Artifacts: Or How the Sociology of Science and the Sociology of Technology Might Benefit Each Other. In W. E. Bijker, T. P. Hughes, \& T. J. Pinch, eds. The Social Construction of Technological Systems: New Directions in the Sociology and History of Technology. Cambridge, MA: MIT Press, pp. 17-50.

Pol, E. \& Ville, S., 2009. Social innovation: Buzz word or enduring term? Journal of SocioEconomics, 38(6), pp.878-885.

Schot, J. \& Rip, A., 1997. The Past and Future of Constructive Technology Assessment. Technology Forecasting and Social Change, 54(1996), pp.251-268.

Schwartz, A. \& Krohn, W., 2011. Experimenting with the Concept of Experiment: Probing the Epochal Break. In A. Nordmann, H. Radder, \& G. Schiemann, eds. Science transformed? Debating claims of an Epochal Break. Pittsburgh: University of Pittsburgh Press, pp. 119-134.

Seyfang, G. \& Smith, A., 2007. Grassroots innovations for sustainable development: Towards a new research and policy agenda. Environmental Politics, 16, pp.584-603.

Smith, G., 2009. Democratic Innovations: Designing Institutions for Citizen Participation, Cambridge: Cambridge University Press.

Soneryd, L., 2016. Technologies of participation and the making of technologised futures. In J. Chilvers \& M. Kearnes, eds. Remaking Participation: Science, Environment and Emergent Publics. London: Routledge, pp. 144-161.

Stilgoe, J., Owen, R. \& Macnaghten, P., 2013. Developing a framework for responsible innovation. Research Policy, 42(9), pp.1568-1580.

Szerszynski, B., 2005. Beating The Unbound: Political Theatre in the Laboratory Without Walls. In G. Giannachi \& N. Stewart, eds. Performing Nature: Explorations in Ecology and the Arts. Frankfurt and New York: Peter Lang, pp. 181-197. 
Thorpe, C., 2010. Participation as Post-Fordist Politics: Demos, New Labour, and Science Policy. Minerva, 48(4), pp.389-411.

Thorpe, C. \& Gregory, J., 2010. Producing the Post-Fordist Public: The Political Economy of Public Engagement with Science. Science as Culture, 19(3), pp.273-301.

Voß, J.-P., 2016. Reflexively engaging with technologies of participation: constructive assessment for public participation methods. In J. Chilvers \& M. Kearnes, eds. Remaking Participation: Science, Environment and Emergent Publics. London: Routledge, pp. 238-260. 